\title{
A TRAJETÓRIA INTERNACIONAL DA LIGHT INFOCON
}

\section{Renato Cotta de Mello}

Universidade Federal do Rio de Janeiro

\section{Angela da Rocha}

Pontifícia Universidade Católica do Rio de Janeiro

\author{
Anne Marie Maculan \\ Universidade Federal do Rio de Janeiro \\ Jorge Ferreira da Silva \\ Pontifícia Universidade Católica do Rio de Janeiro
}

No início de junho de 2010, Alexandre Beltrão Moura, presidente do conselho de administração da Light Infocon Tecnologia S.A., uma empresa brasileira de software sediada em Campina Grande, Paraíba, preparava uma apresentação para o congresso da Academy of International Business, principal entidade científica da área de negócios internacionais, que se realizaria pela primeira vez no Rio de Janeiro, dentro de três semanas. Alexandre Moura iria participar de um painel de empresários de TI, e lhe fora pedido que traçasse a trajetória de internacionalização de sua empresa. Enquanto finalizava sua apresentação, ele refletia sobre o quanto a empresa havia avançado em seu processo de internacionalização e nos passos seguintes que deveria dar para prosseguir nessa trajetória, dados os recursos limitados da firma e as oportunidades disponíveis em distintas partes do mundo.

\section{CFGV-EAESP/RAE 2011}

Todos os direitos reservados. Permitidas a citação e a reprodução parcial ou total, desde que identificada a fonte. Em caso de dúvidas, consulte a Redação: gvcasos.redacao@fgv.br; (11) 3799-3717 
A estratégia adotada pela empresa, de alta flexibilidade e risco controlado, parecia adequada à continuidade da expansão internacional, mas talvez fossem necessários alguns ajustes para trabalhar melhor a multiplicidade de oportunidades e desafios. Em particular, o empresário se questionava quanto a se a empresa deveria estabelecer um escritório de vendas no Chile, para posterior expansão para Austrália e Nova Zelândia, ou se deveria aprofundar a presença nos mercados em que já se encontrava presente. Em sua volta do congresso, pretendia discutir essa questão com os demais dirigentes da empresa.

\section{A indústria brasileira de software}

A política brasileira de informática, desenvolvida e implementada ao longo das décadas de 1970 e 1980, trouxe, na opinião de alguns, prejuízos ao país, ao limitar o acesso a produtos de tecnologia da informação a vários setores da indústria. Para outros, porém, a reserva do mercado brasileiro de produtos de informática teria propiciado, indiretamente, a formação de uma geração de técnicos e engenheiros que, mais tarde, seria responsável pela expansão da indústria brasileira de software. De fato, as estimativas são de que, ao final da década de 1980, já se encontrassem cerca de 500 empresas produtoras de software de capital nacional, a maioria delas de pequeno porte. Os principais campos para desenvolvimento de tecnologia na área de software, no Brasil, vieram de aplicações específicas nas áreas de automação bancária e de serviços de telecomunicações.

Com o fim da reserva de mercado e a globalização, além de mudanças radicais na tecnologia de informação, ocorreu, já a partir do início da década de 1990, o surgimento de grande número de empresas de software, de micro, pequeno e médio portes, voltadas à produção de aplicativos de gestão. As peculiaridades do mercado brasileiro também haviam propiciado a expansão de algumas empresas de grande porte no setor, particularmente aquelas ligadas a bancos, pois a automação bancária mostrava-se uma necessidade diante da elevada e persistente inflação brasileira que perdurou até meados da década de 1990, quando foi implantado o plano de estabilização da economia (conhecido como Plano Real). Além dessas, algumas empresas privadas independentes haviam crescido, como era o caso da Datasul e da Politec. 
Na década de 1990, o governo brasileiro adotou uma nova política voltada para o desenvolvimento do setor de tecnologia da informação. A partir de 1993, além disso, foi criado o Softex, Programa Nacional de Software para Exportação, coordenado pelo CNPq (Conselho Nacional de Desenvolvimento Científico e Tecnológico) e com suporte financeiro da Finep (Financiadora de Estudos e Projetos) e do BNDES (Banco Nacional de Desenvolvimento Econômico e Social). Em 1996, foi criada, então, a Associação para Promoção da Excelência do Software Brasileiro, a Softex, como gestora do programa.

Com as mudanças no ambiente institucional brasileiro, no ambiente global e na tecnologia da informação, as portas estavam abertas à expansão do número e tamanho de empresas de software no país. O mercado alargou-se e o setor de software cresceu expressivamente, tornando o Brasil o sétimo produtor mundial de software e serviços de TI. A taxa média de crescimento, a partir de 1995, encontrava-se em torno de $11 \%$ ao ano. Em 2006, a Softex estimava a existência de cerca de 59 mil empresas de software e serviços de TI no Brasil, das quais cerca de 12 mil eram produtoras de software. Em 2009, a Softex projetava que o número total de empresas de software e TI teria crescido para aproximadamente 68 mil. Tratando-se de estimativas e dados projetados, há dúvidas, no entanto, quanto ao número real de empresas produtoras de software no país.

No entanto, apesar de se haver tornado um dos principais mercados mundiais de software e serviços de TI, o país apresentava baixa participação das exportações, sendo a maior parte do software produzido no país absorvida pelo próprio mercado brasileiro. Segundo dados da Softex, estimava-se que, em 2006, o Brasil houvesse exportado apenas US\$ 885 milhões de software, uma cifra inexpressiva quando comparada à de países como Índia e China. Para se ter uma ideia, a indústria indiana de software e serviços de TI, em 2009, obteve receitas de 73 bilhões, sendo cerca de 50 bilhões provenientes da exportação. No entanto, apesar de ter um longo caminho ainda a percorrer, o setor de TI brasileiro vinha avançando. Por exemplo, entre 2007 e 2010, a classificação do Brasil no Índice de Competitividade do Setor de TI havia passado para $39^{\circ}$, quatro posições à frente da que ocupava em 2007. Na América Latina, a posição do Brasil ainda era superada pela do Chile. Com relação aos BRIC, Índia $\left(34^{\circ}\right)$ e China $\left(38^{\circ}\right)$ ainda estavam um pouco à frente do Brasil, mas a Rússia ficava atrás, em $46^{\circ}$. 
De acordo com a World Intellectual Property Organization, 9\% dos pedidos de patentes registrados pelo Brasil entre 2007 e 2010 referiam-se ao setor de TI.

Além disso, as exportações brasileiras encontravam-se, em 2005, bastante concentradas, com apenas 30 empresas responsáveis por mais de $95 \%$ das exportações de software, sendo 22 empresas privadas brasileiras e oito multinacionais. Segundo pesquisa realizada pela Universidade Estadual de Campinas e pela Softex, em 2004, eram os seguintes os mercados de destino das exportações brasileiras: Estados Unidos (30\%), União Europeia (20\%), Mercosul (18\%) e outros países da América do Sul (13\%). Os resultados desse estudo mostraram, ainda, que a principal barreira percebida pelos empresários para ampliação das exportações brasileiras era a “imagem-país”, ou seja, o Brasil não era identificado, no mercado internacional, como produtor de software. Os principais canais utilizados pelas empresas desenvolvedoras de software para acesso ao mercado internacional eram as feiras e eventos internacionais, convites de outras empresas para integrar projeto, consórcios de exportação. Algumas empresas utilizavam como canal de distribuição a rede de empresas multinacionais, como no caso das produtoras de games.

\section{O Cluster de TI de Campina Grande}

A formação de clusters de tecnologia da informação (às vezes chamados polos tecnológicos ou parques tecnológicos) é um fenômeno observado em vários países, como Estados Unidos (Vale do Silício) e Índia (por exemplo, os clusters localizados nas cidades de Mumbai, Bangalore e Hyderabad). No Brasil, também se observa a formação de clusters, tanto espontaneamente quanto por iniciativa das várias esferas de governo.

O estado da Paraíba ocupa o terceiro lugar entre os estados do Nordeste brasileiro em termos de investimento em pesquisa científica e, em 2009, o número de empresas que atuavam no setor de TI alcançava um total de 350 empreendimentos. Especificamente na cidade de Campina Grande, encontrava-se um dos 74 polos tecnológicos do país. A cidade concentrava o maior número de $\mathrm{PhD}$ por habitantes do Brasil. Campina Grande, à época, já começava a se tornar um importante centro de tecnologia do Nordeste. Essa vocação para a tecnologia em uma área afastada dos grandes centros 
urbanos do país se devia, fundamentalmente, à existência de importantes organizações tecnológicas e universitárias na cidade: a Universidade Federal de Campina Grande; o campus da Universidade Estadual da Paraíba; e, mais recentemente, o Instituto Federal de Educação, Ciência e Tecnologia da Paraíba (campus Campina Grande), a Fundação Parque Tecnológico da Paraíba e outras 10 instituições privadas de ensino superior. A existência dessas instituições de ensino superior e pesquisa proporcionou o suporte necessário ao surgimento de grande número de empresas de tecnologia na década de 1980, ainda sob a égide da reserva de mercado de informática. Mas a base tecnológica estabelecida permitiu a essas empresas se manterem inovadoras e competitivas.

Os números comprovam um forte crescimento do setor no estado da Paraíba. Em dois anos, um grupo de 44 empresas cresceu o faturamento em 623\%, passando de R \$3,4 milhões, em 2005, para R\$ 24,6 milhões, em 2007. No mesmo período, as exportações aumentaram em 218\%, estas feitas apenas por nove empresas que venderam seus produtos para 30 países de todos os continentes, entre os quais Estados Unidos, Canadá, Argentina, México, Portugal, Hungria, Espanha, China, Angola e Austrália. Do total de empresas do setor de TI no estado, 17 empresas (cerca de 5\% do total) exportavam. As empresas do setor atuavam basicamente com banco de dados, capacitação e treinamento, comércio, consultoria, desenvolvimento de software, desenvolvimento para web, hospedagem na internet, indústria de hardware, processamento de dados, publicidade e propaganda, redes, robótica, segurança de dados e telecomunicações.

\section{A Light Infocon}

As origens da Light Infocon datam de 1983, com uma empresa chamada Infocon Tecnologia, fundada em Campina Grande por Reginaldo Lima e um sócio canadense que era professor da Universidade Federal de Campina Grande, ambos formados em Engenharia Eletrônica (esse sócio, posteriormente, saiu da empresa). Agregou-se à empresa o engenheiro eletrônico Alexandre Moura, que vinha de uma família de empresários da região. A Infocon Tecnologia, desde sua fundação, mostrava-se uma empresa inovadora, com forte orientação empreendedora. 
Mudanças no cenário nacional e internacional do setor de TI, na década de 1990, começaram a inquietar os sócios, que se davam conta de que as mudanças exigiam empresas maiores, que tivessem ramificações geográficas em outros locais e escala suficiente para realizar investimentos expressivos em pesquisa e desenvolvimento. Em outras palavras, impunha-se aumentar o tamanho da empresa, sua diversificação geográfica e de produtos. Alexandre Moura observou:

"Nós temos uma característica, por estar nesse mercado há 25 anos, que é a de olhar sempre um pouco para frente para ver o que está acontecendo. Assim, em meados da década de 1990, ficou claro que, se não aumentássemos o tamanho da empresa, não fizéssemos fusões e juntássemos com novas tecnologias de terceiros, nós não iríamos muito longe. Então, como já havia uma parceria com a Light Software, uma empresa de Brasília, e já tínhamos alguns produtos desenvolvidos de forma conjunta, fizemos uma fusão com a mesma, dando origem, em 1995, à Light Infocon S.A.”.

A fusão deu-se de modo suave, sem contratempos, uma vez que as duas empresas já tinham afinidades há algum tempo, dado que, além de desenvolverem novos produtos de maneira conjunta, seus dirigentes conheciam-se pessoalmente de longa data, suas tecnologias já estavam alinhadas, e até os próprios clientes das duas empresas já se conheciam. Alexandre Moura explicou:

“A parte comercial da Light era mais forte do que a nossa. Nós tratávamos só com clientes corporativos e a Light trabalhava mais com o governo. Tinha também a questão das revendas. A Light já dispunha de uma rede de revendas no Brasil e nós não. Então foi um ajuste... Eu acho que deu certo desde o início".

Ao final de 1995, concretizou-se a união das duas empresas. Nascia assim a Light Infocon S.A., sociedade anônima de capital fechado, sediada em Campina Grande, e com filial em Brasília, capital federal. Os sócios eram Alexandre Beltrão Moura, presidente do Conselho de Administração, engenheiro eletrônico, Mestre em Engenharia Elétrica com MBA em Software Business, nos EUA; Jairo Fonseca, fundador e sócio majoritário da Light Software, que era o diretor-presidente, sediado no escritório em Brasília, era analista de sistemas e havia trabalhado em importante órgão governamental 
da área de TI em Brasília, tendo estabelecido conexões importantes em todo o setor na capital federal; Reginaldo Lima, que exercia a função de diretor de operações, era bacharel em Ciências da Computação e tinha um MBA em Comércio Eletrônico.

Em 2010, a empresa era uma sociedade anônima de capital fechado, com um quadro de aproximadamente 40 funcionários no Brasil, distribuídos entre a matriz em Campina Grande e a filial em Brasília, além de dois funcionários no exterior, locados em seu escritório de Portugal. A trajetória da empresa era marcada por diversos prêmios nacionais e internacionais, entre os quais: o Prêmio Finep de Inovação Tecnológica, região Nordeste; o Prêmio Assespro (duas vezes); o Editor's Choice, da PCWorld da Espanha; o Top of the World, da revista SCO World Magazine; o Microsoft DesignWin; e um prêmio no Asia Software Business Meeting.

O faturamento da empresa era estimado em torno de 10 milhões de reais, sendo cerca de $15 \%$ provenientes de exportação. A linha de produtos estava voltada para um mercado relativamente amplo. O principal produto era um software de banco de dados textual multimídia orientado a objeto, que envolvia o desenvolvimento de ferramentas de recuperação de textos multimídia, tais como sons, imagens e vídeos, simultaneamente. O Anexo 1 apresenta os principais produtos da Light Infocon.

\section{Processo de internacionalização}

A internacionalização antecedeu a criação da Light Infocon, uma vez que a Infocon Tecnologia já havia iniciado suas exportações em 1988, com uma venda realizada para os Estados Unidos. Na ocasião, a empresa desenvolvia seus softwares para um sistema operacional distinto daquele utilizado posteriormente, mas que era considerado o padrão internacional, e os produtos da empresa brasileira conseguiam ser mais específicos em suas aplicações do que seus concorrentes no exterior. Alexandre Moura explicou como surgiu essa oportunidade:

“Naquela época, a Infocon Tecnologia trabalhava com outro tipo de sistema operacional, outra base tecnológica. Nós, eu e meu sócio canadense, tínhamos muitos contatos no exterior. E tinha meu irmão, que havia feito Doutorado no Canadá. Eu tinha estudado nos Estados Unidos num intercâmbio... 
$\mathrm{E}$, coincidentemente, havia algumas pessoas que eu já conhecia há certo tempo, que estavam na Califórnia, trabalhando no mesmo tipo de plataforma, só que não com tanta especificidade quanto nós. E aí, em conversas, surgiu a oportunidade”.

Pouco tempo depois da realização da primeira exportação, em 1989, a empresa montou um escritório de vendas próprio em San Jose, na Califórnia, com um parceiro local. Ainda em 1989, a empresa realizou uma venda para o Canadá, seguindo-se de exportações para a França, Itália e Espanha. A empresa realizava um esforço pró-ativo de vendas em feiras e eventos no exterior, o que era considerado um elemento importante de sua estratégia comercial, uma vez que aí eram gerados muitos novos contatos. $\mathrm{O}$ uso de escritórios comerciais era considerado uma estratégia importante para dar credibilidade e confiança aos clientes: "Você já tem referências de clientes, tanto no Brasil quanto fora... E aí a coisa começa a acontecer, facilita, você começa a conseguir parceiros...”.

A empresa continuou a explorar oportunidades de vendas nos Estados Unidos. Assim, com o advento da Light Infocon, foi criada, em 1996, na Flórida, a Light Infocon Technology. Essa subsidiária comercial foi desativada dois anos depois, em 1998. Alexandre Moura explicou a visão da empresa com relação à montagem e posterior desativação de escritórios e subsidiárias de vendas:

"Para vender para os Estados Unidos, ou para qualquer outro lugar, é preciso ter uma presença por determinado período. Na Flórida havia um cliente interessante que precisava ser trabalhado. Não só um, alguns... E até estabelecer um parceiro local que pudesse atender bem este cliente, montamos uma estrutura lá, porque o cliente tinha que ser bem atendido... Mas quando a coisa começou a ficar mais azeitada, chegamos à conclusão de que não precisávamos mais do escritório. Principalmente com o advento da internet... Para começar em um mercado, não tem jeito, você tem que estar presente."

Entre os benefícios percebidos pelo empresário em estabelecer uma presença física, ainda que temporária, em outro mercado, estava a necessidade de aprender sobre as diferenças culturais e as práticas de negócio em mercados estrangeiros, que diferiam do Brasil. A direção da empresa acreditava 
que a presença física em outro mercado gerava conhecimento e demonstrava aos próprios executivos e técnicos as diferenças com relação ao Brasil, tornando-os mais aptos a lidar com as diferenças.

A entrada da Light Infocon na China, ao final da década de 1990, foi o resultado de oportunidade e relacionamentos. A Light Infocon, juntamente com outras empresas brasileiras, participou da implantação de um escritório compartilhado - o China Office - com o apoio dos governos chinês e brasileiro. Na época, Alexandre Moura era membro da Softex e da Associação Brasileira das Empresas de Tecnologia da Informação (Assespro) - a mais representativa associação brasileira de empresas do setor. Essas instituições estavam interessadas em introduzir o software brasileiro no mercado da China e foi montado, então, um projeto com a participação de várias empresas, entre as quais a Light Infocon, com apoio da Finep e do Serviço de Assistência à Pequena e Média Empresa (Sebrae). O China Office foi montado no Instituto de Tecnologia de Software Chinês, ligado à Academia Chinesa de Ciências, "um órgão do governo chinês que cuida da parte de C\&T do país como um todo, como se fosse um ministério", que proporcionava incubação, financiamento e apoio a joint ventures. A Light Infocon adaptou alguns de seus produtos aos caracteres chineses.

A experiência, que durou até 2002, foi considerada válida, tendo gerado alguns negócios para a empresa naquele país, o que levou à continuidade de suas atividades naquele mercado. $\mathrm{O}$ passo seguinte foi estabelecer um representante local, de modo a colher os benefícios da primeira investida por meio do escritório compartilhado e dispor de um parceiro local, que viria a contribuir com o seu guanxi, ou seja, sua própria rede de relacionamentos. Além disso, permitia a manutenção da própria rede de relacionamentos que a empresa havia estabelecido na China no decorrer de suas atividades iniciais com escritório compartilhado. O empresário declarou a esse respeito: "Procuramos aliar a troca de conhecimento técnico para avançar naquele mercado. Não dá para avançar sem um apoio local e uma boa rede de relacionamentos". Os resultados da experiência na China vinham frutificando, cerca de $20 \%$ das exportações da empresa eram dirigidas àquele mercado em 2010.

Outro movimento na trajetória de internacionalização da empresa ocorreu no ano de 2001, com a abertura de uma filial em Melbourne, na Austrália. Esse movimento foi, porém, bastante peculiar e 
diferenciado dos anteriores. Nesse país, a empresa estabeleceu presença virtual, e não física, por meio de um site de comércio eletrônico, destinado apenas à comercialização para pessoas jurídicas no mercado internacional, beneficiando-se dos incentivos fiscais oferecidos pelo governo australiano, o que a tornava mais competitiva em preços.

O mercado seguinte foi Portugal, em 2003. Dessa vez, a Light Infocon estabeleceu escritório de vendas próprio na cidade de Aveiro, que se destacava como polo de empresas de tecnologia portuguesas. Tratava-se de uma iniciativa associada ao programa europeu AL-Invest, que fomentava parcerias entre empresas latino-americanas e europeias. O escritório foi estabelecido com um parceiro local, a NexLogic Business Solutions, e pretendia atender não apenas a clientes locais, mas também aos de outros países europeus, como declarou Alexandre Moura: "Agora temos uma base para alavancar novos negócios na Europa”. A Light Infocon alocou dois funcionários no escritório português: um brasileiro, com experiência de trabalho em Portugal, e um português. Os dois funcionários haviam trabalhado anteriormente em empresas multinacionais e conheciam o setor. $\mathrm{O}$ escritório, que foi posteriormente transferido para a cidade do Porto, permitiu à Light Infocon conquistar novos clientes.

Na opinião de Alexandre Moura, o escritório em Portugal gerava diversos benefícios. De um lado, havia a facilidade de conquista de novos clientes, tanto no país quanto em países vizinhos, como a Espanha. Em segundo lugar, permitia oferecer melhor atendimento a clientes estatais, já que esses eram muito exigentes no que se referia a um atendimento próximo e constante. Por exemplo, um cliente importante obtido na Espanha era o Ministério da Defesa, por meio da Polícia Federal espanhola, e esse cliente exigia presença constante. Em terceiro lugar, ampliava a rede de relacionamentos da empresa, dando acesso a novos mercados e abrindo novas oportunidades. Por exemplo, o escritório português gerava relacionamentos importantes com empresas portuguesas, que acabaram por permitir exportar os produtos da Light Infocon para o mercado de Angola em parceria com elas. Alexandre Moura explicou que "praticamente todas as companhias que exportam continuamente para Angola [...] o fazem através de parcerias com empresas portuguesas ou do próprio país. Ninguém vai às cegas”.

O Anexo 2 apresenta os mercados de atuação da Light Infocon em 2010. 


\section{Gestão da ação internacional}

Quando a Light Infocon foi criada, já havia uma expectativa de ação internacional, aproveitando-se da experiência da Infocon Tecnologia. O interesse no mercado internacional derivava da percepção de que este poderia trazer importante aprendizado para a empresa e torná-la mais competitiva no mercado internacional, como observou o empresário Alexandre Moura:

"O nosso business plan não focava determinados mercados. Focava o quê? Que a empresa tinha que exportar. Porque os concorrentes estão aqui dentro, no Brasil, então temos que entender isso... Mas uma coisa é você fazer negócio no Brasil, outra coisa é fazer negócio lá fora. Então, uma forma de ganhar experiência é ir ao mercado".

O primeiro plano de negócio estabeleceu que, a partir do primeiro ano em que a empresa exportasse, a cada ano subsequente haveria uma expansão para um país diferente: “Ou seja, a cada ano teria que ser em outro local. Isso não estava escrito em pedra, mas a cada mercado pensávamos qual seria o próximo alvo que a empresa iria atacar".

A expansão da Light Infocon, a partir dos Estados Unidos e do Canadá, para a França e para a Itália era considerada pelo empresário como fruto da interconexão entre seus clientes naqueles países com empresas francesas e italianas:

"O Canadá tem aquela parte francesa, e com isso fica mais fácil conversar com o pessoal da França. Aí você conhece uma empresa na França que trabalha com os canadenses, que já usam o seu produto. Você trabalha com empresas nos Estados Unidos em que há muito descendentes de italianos, que apresentam sua empresa a uma coligada lá na Itália, que está precisando do mesmo produto. E por aí vai".

De modo similar, o conhecimento de empresários portugueses havia criado oportunidades que permitiram exportar para Angola. Alexandre Moura estava convencido de que o estabelecimento de uma rede de relacionamentos servia como ponte para outros mercados, particularmente em seu setor de 
atuação: "É aquela questão, nesse ramo - eu não sei como é nos outros, eu não posso falar - mas, em tecnologia, é ponto pacífico a questão de você ter seu network. Sem isso, não se consegue fazer nada”.

Como se observou, a Light Infocon usava três estratégias para as vendas no exterior: exportações do Brasil, exportações diretas da Austrália via portal B2B e presença física no exterior. Nesse último caso, a estratégia de internacionalização consistia em abrir inicialmente um escritório comercial para atuação direta, conhecer o mercado, desenvolver parcerias e nomear um parceiro como representante, fechando o escritório.

Os principais instrumentos de contato com os mercados externos eram as feiras comerciais e a internet. As feiras internacionais eram uma forma pró-ativa de marketing exercida pela empresa. Como expositora, participava há anos das maiores feiras internacionais do setor, e a direção considerava excelentes os resultados obtidos. Por exemplo, em uma feira na Espanha, contatos com um grupo espanhol acabaram levando à parceria para distribuição de software naquele país. Em muitos casos, a Light Infocon dividia com outras empresas o estande patrocinado pela Apex Brasil.

A internet era considerada fundamental, tanto para a realização de vendas no exterior quanto para a manutenção e upgrade do software exportado. O site da empresa era, geralmente, o meio utilizado por novos clientes no exterior para a primeira abordagem, ou seja, para ter o primeiro contato com os produtos oferecidos pela Light Infocon: "Hoje é fundamental. Eu não vejo como expandir um negócio sem isso. Além de novos negócios, para a manutenção dos nossos produtos no exterior, a internet é o um instrumento base. Eu não consigo mais nos ver sem internet".

\section{Perspectivas}

Os movimentos da empresa na direção de sua internacionalização apresentam características dinâmicas e traduziam intenções de atingir mais dois continentes de maneira simultânea: África e Oceania. A Light Infocon não planejava incursões diretas na América Latina, preferindo delegar a seus parceiros espanhóis a responsabilidade por revender o software em espanhol para os países latinoamericanos. Comentou a esse respeito Alexandre Moura, em entrevista a um jornal: "O ideal seria ter 
um escritório em Buenos Aires, mas temos que selecionar onde investir nossos recursos". Apesar disso, a empresa planejava ingressar no mercado do Chile: "É um mercado pequeno, só que eles são uma porta de entrada para a Nova Zelândia. Sei de algumas empresas brasileiras, de outros setores, que entraram no mercado neozelandês a partir do Chile".

Para a direção da empresa, a internacionalização proporcionava diversos benefícios. Em primeiro lugar, havia a oportunidade de desenvolvimento tecnológico, que resultava dos contatos entre seus engenheiros e técnicos e os de empresas parceiras ou clientes no exterior, ou ainda por ocasião de participação em eventos em outros países. A simples exposição do pessoal técnico a outras culturas proporcionava um aprendizado valioso para a empresa. Os contatos informais eram frequentemente uma rica forma de aquisição de experiência e conhecimento. Alexandre Moura observou: "Se você não juntar nossos técnicos com técnicos de outras empresas, se eles não trocarem ideias, não forem jogar totó, jogar basquete, pingue-pongue ou tênis, se não conviverem, nada acontece. Porque é aí que fluem ideias. Essa indústria é uma indústria de ideias, de inovação. É direto. Essa troca é muito interessante.”

Em segundo lugar, havia a questão financeira. Por um lado, Alexandre Moura mostrava-se satisfeito com os resultados obtidos por meio das exportações, indicando que a rentabilidade obtida no exterior era superior à que obtinha no Brasil: "Graças a Deus, ao nosso trabalho e também à sorte, nós nunca perdemos dinheiro, e hoje os lucros das exportações estão bastante atraentes". Por outro, ele achava interessante para a empresa dispor de uma carteira de moedas, de modo a reduzir o risco cambial, ainda que, no momento, não fosse interessante repatriar os lucros, dado que a taxa de câmbio não era atraente: "Hoje está ruim porque o dólar está baixo... Estou com várias cartas de crédito que eu não troquei ainda porque fechamos um negócio em Angola quando o dólar estava a R \$2,25 e hoje está a R\$1,62”.

Finalmente, havia um terceiro benefício relacionado ao posicionamento da empresa no mercado doméstico. Moura acreditava que a presença no mercado internacional aumentava a credibilidade da empresa junto aos clientes no Brasil e valorizava sua imagem. Ele explicou: "Quando você está abordando um cliente novo no Brasil e ele fica sabendo que você tem negócios fora, quando ele sabe 
que você exporta, tem clientes na Europa, nos Estados Unidos, na China, então ele passa a valorizar mais a sua empresa".

Assim, a internacionalização era percebida pela alta direção da Light Infocon como um caminho sem volta, cujos benefícios de longe ultrapassavam os desafios que se colocavam à empresa. Em linhas gerais, a intenção era aumentar mais a presença da empresa no exterior do que no Brasil: “A métrica do nosso plano é aumentar o faturamento no Brasil e, proporcionalmente, crescer mais fora do que aqui". O crescimento seria pautado por três critérios: tamanho da oportunidade do negócio que se apresentasse; condições locais de trabalho no país onde surgisse a oportunidade; e perspectivas de longo prazo relacionadas a essa oportunidade.

Todas essas questões passavam pela cabeça de Alexandre Moura ao preparar sua apresentação para o encontro da Academy of International Business. A preparação da apresentação havia sido uma oportunidade para rever o histórico da empresa e sua trajetória internacional. Mas algumas questões ainda se colocavam quanto aos caminhos escolhidos na internacionalização: prosseguir ou mudar? 


\section{Anexo 1 \\ Produtos da Light Infocon}

\section{Banco de dados textual multimídia}

O Lightbase é um banco de dados textual multimídia que reúne, de maneira única, um ambiente de desenvolvimento rápido de aplicações e um poderoso servidor de dados tridimensional com recuperação textual e um servidor de aplicações e relatórios.

\section{Digitalização de documentos e tratamento da informação}

O Goldenscanner é uma ferramenta voltada para digitalização de documentos, dotando a sua empresa de recursos que permitam um melhor tratamento das informações, diminuindo custos de armazenagem, reduzindo o consumo de papel e agilizando a localização desses documentos.

\section{Aplicação GED}

O Goldendoc fornece um conjunto de frameworks, de tecnologia aberta, para a implantação de soluções voltadas para gerenciamento de informações focando a captação, ajustes, distribuição e organização dos conteúdos para apoio aos processos operacionais da empresa.

\section{Workflow}

O Goldentrack cria, tramita e monitora todos os documentos da sua organização de forma fácil, rápida e transparente. Além disso, ele permite uma total transparência no acompanhamento dos processos.

Fonte: documentos da empresa

\section{Anexo 2}

Atuação da Light Infocon em 2010

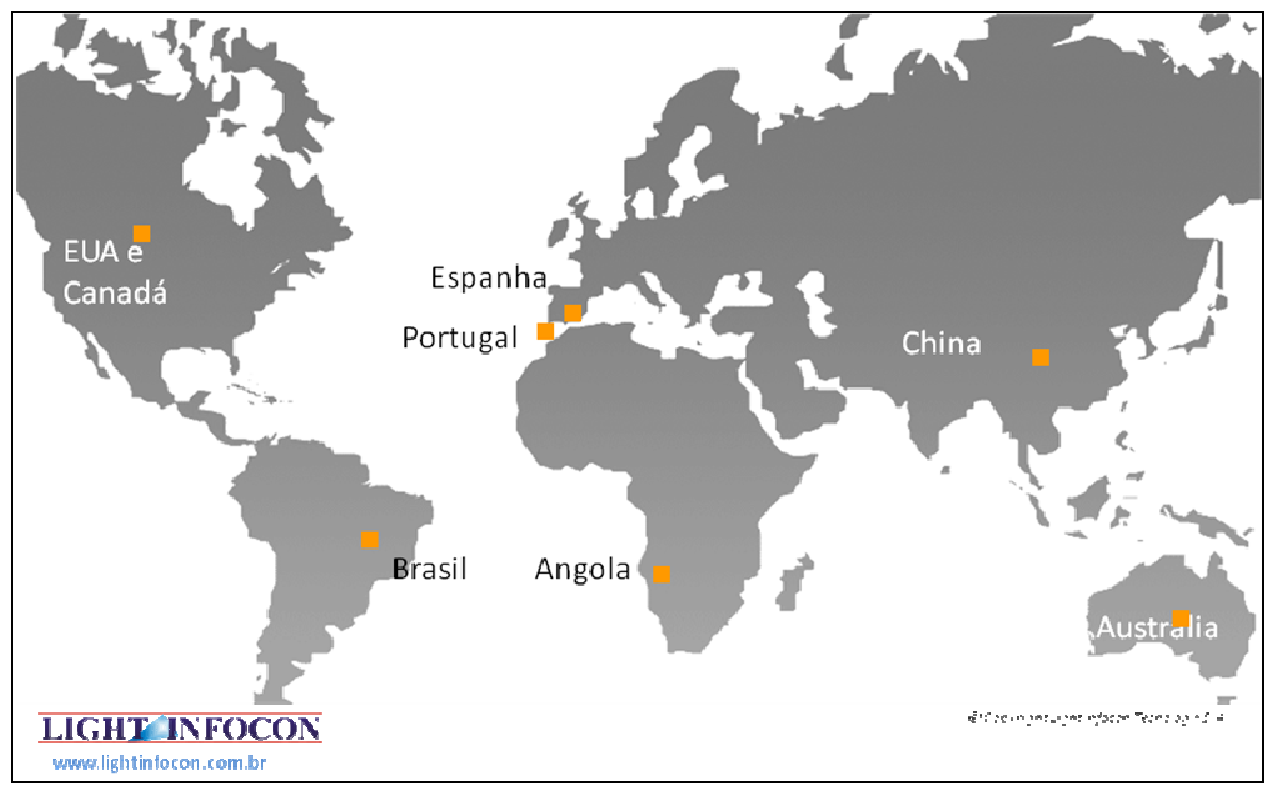

Fonte: documentos da empresa 